\title{
Dense Nanostructured Calcium Phosphate Coating on Titanium by Cold Spray
}

\author{
A. M. Vilardell ${ }^{1}$, N. Cinca ${ }^{1}$, I. G. Cano ${ }^{1}$, A. Concustell ${ }^{1}$, S. Dosta ${ }^{1}$, J. M. Guilemany ${ }^{1}$ \\ ${ }^{1}$ Centre de Projecció Tèrmica (CPT). Dpt. Ciència dels Materials i Enginyeria Metal.lúrgica. Universitat \\ de Barcelona Martí i Franquès 1, E-08028, Barcelona, Spain.
}

\author{
S. Estradé2, A. Ruiz-Caridad², F. Peiró \\ ${ }^{2}$ LENS-MIND/IN2UB, Dept. d'Electrònica, Universitat de Barcelona, c/ Martí i Franquès 1, 08028 \\ Barcelona, Spain
}

\begin{abstract}
This article deals with the understanding of building-up mechanisms of bioactive nanocrystalline hydroxyapatite coatings by Cold Spray, revealing very promising results in contrast to more conventional techniques such as Plasma Spray. A full characterization of feedstock and coatings is provided. The agglomerated structure of the powder proved to be suitable to obtain successfully thick hydroxyapatite coatings. A crystallite size below $\sim 20 \mathrm{~nm}$ in the powder and the as-sprayed coatings is calculated by the Rietveld Xray refinement method and agreed by Transmission Electron Microscopy. Some wipe tests were carried out on Ti6Al4V substrates in order to study the deposition of single particles and the nanoscale features were evaluated. The resulting structure indicates that there is no delimitation of particle boundaries and the overall coating has been formed by effective compaction of the original nanocrystallites, leading to consistent and consolidated layers.
\end{abstract}

\section{Keywords}

Coating; Nanocrystalline Calcium Phosphate; Cold Spray; Electron Microscopy;

\section{Introduction}

Hydroxyapatite plasma sprayed (PS) coatings have been widely used in orthopedic surgery to reconstruct hip and knee joints. Studies reveal that once HA is implanted, it has the ability to bond directly to the bone, to achieve earlier and greater fixation and to reduce the healing time. Moreover, these coatings can successfully reduce the incidence of thigh pain and femoral osteolysis [1]. Despite the existence of controversy between the use of hydroxyapatite (HA) coatings and porous metallic coatings, HA coatings have shown to have faster bone growth [2].

From all methods to produce HA coatings: dip coating, electrophoretic deposition, hot isostatic pressing, ion-beam sputtering, among others, PS appears to be the most favorable mainly because of the high deposition rates at low cost. Nevertheless, the high temperatures and high cooling rates from the PS technique lead to HA decomposition with the formation of a large content of amorphous phasesinto many different calcium phosphate phases with a high dissolution rates in body fluids. The ideal HA coating for orthopedic implants would be one with strong cohesive strength, good adhesion to the substrate and low porosity [3], while few works attempt to report a preferred value of crystallinity. Actually, much interest has arisen on nanocrystalline coatings due to the small crystal size which improves cell proliferation and, therefore, the osteoconductive properties of the coatings coming from their higher degradability [4]. Mainly due to the possibility of controlling coating crystallinity, low temperature depositing processes such as biomimetic deposition, electrochemical deposition and solution deposition, are of interest. However, some are time-consuming and their mechanical properties are poor. Others such as Cold Spray (CS) [5], Aerosol Deposition (AD) [6,7,8] and nano-particle deposition system (NPDS) $[9,10]$ have become of interest during the last decade.

HA layers have already been successfully achieved by $\mathrm{AD}[11,12,13]$. AD mainly consists on a carrier gas supply system with mass flow control, a powder chamber containing feedstock powder, and a deposition chamber with motored $\mathrm{X}-\mathrm{Y}$ stage and a nozzle evacuated by a rotary vacuum pump; in addition, high vacuum conditions are necessary. Dense structures occur by the reduction of crystallite size by fracture or plastic deformation; however, the bonding mechanism between the fine particles themselves has not been clarified yet [8]. Dense nanostructured HA coatings on titanium were achieved by fracturing HA particles into nanoscale fragments to form highly dense coatings with a theoretical density of $98.5 \%$. TEM micrographs reveal an average grain size of $16.2 \mathrm{~nm}$ and amorphous phases, nonetheless with a good bonding strength of $30.5 \pm 1.2 \mathrm{MPa}$ [11]. Further, a heat treatment at $400^{\circ} \mathrm{C}$ was required to avoid amorphous HA phases, leading to an increase in average grain size up to $29.3 \mathrm{~nm}$; heat treatments up to $500^{\circ} \mathrm{C}$ 
further lead to a grain size of $99 \mathrm{~nm}$, showing a decrease in biological properties. It was concluded that grain size significantly affects biocompatibility. Webster et al. [14] reported that osteoblast functions on ceramics with grains smaller than 100nm were significantly enhanced compared with larger grains. So, the production of nanocrystalline HA coatings on titanium seems desirable for implants if it can be accomplished at low temperature.

A difference between $\mathrm{AD}$ and $\mathrm{CS}$ is that $\mathrm{AD}$ uses submicrometer particles as feedstock while CS was originally more suitable for metallic feedstock within the 5-50 $\mu \mathrm{m}$ sized range and does not use vacuum conditions. CS is a solid-state coating deposition method where feedstock powders are propelled toward a gas jet at supersonic velocities up to $1100 \mathrm{~m} / \mathrm{s}$ and lower temperatures than the melting point of the material, with minimum thermal input. Metallic particles undergo plastic deformation and adhere to the substrate. Temperature- and oxygen-sensitive materials such as polymer and titanium are successfully densely deposited [15,16,17]. Due to the inherent brittleness, ceramic deposition by CS is still a challenge and ceramic particles are deposited as cermets [18] or co-deposited with other ductile materials (e.g titanium) [19,20].

Lately, the research of HA CS coatings has been carried out with a lot of interest within the biomedical field. Some attempts of spraying HA were performed on ductile substrate materials with successful results. Lee et al. [21] deposited a HA coating homogeneously onto polyetheretherketone (PEEK) disk implants enhancing in vitro biocompatibility and promoting in vivo osseointegration. Noorakma et al. [22] improved the biodegradability of magnesium alloy by the re-precipitation of an apatite layer as a consequence of HA coating onto a magnesium alloy and HA-graphene composites were deposited as well [23]. Recently, we focused on the deposition mechanisms of HA by CS and reported the feasibility of the deposition of sintered HA powders by dynamic fragmentation due to pore collapse+cracking and crushing mechanisms of the HA particles, with a considerable decrease in crystal size [24]. Apart from this, only numerical investigations have faced the issue of HA deposition by CS, primarily analyzing the influence of nozzle and particle geometry in particle velocity [25,26].

The present article is aimed at studying the build-up of CS coatings from an agglomerated nano-crystalline HA powder, and compare it with the previous studies for a porous sintered crystalline HA powder [24].

\section{Materials and methods}

An agglomerated powder from Medicoat (France) was used as feedstock. The particle size has been measured using a Laser Diffraction Particle Size Analyser Beckman Coulter LS 13320. The density of the powder was measured through the standard specification ASTM B-962-08; the density is evaluated introducing in a flask of $25 \mathrm{ml}$ a known mass of the powder in consideration and filling with a high wettable liquid with a known density, here cyclohexanone. Knowing the density of the dissolvent, the powder density can be calculated the following equation 1 the real density:

$$
\text { (Eq.1) } \rho=\frac{m_{p}}{\left(25-\frac{m_{t}-m_{p}}{\rho_{\text {liq }}}\right)}
$$

where $m_{p}$ is the mass powder introduced, $m_{t}$ is the total mass (powder + cyclohexanone) and $\rho_{\text {liq }}$ is the cyclohexanone density at working temperature, and the density of both powder and coating were calculated by Archimies method using cyclohexanone. Thermogravimetry (TG) was carried out by SDT 2960 (TA instruments) while FTIR by Thermo SCIENTIFIC NICOLET In10 MX of reflection with MCT detector. FTIR measurements were carried out in a Scientific Nicolet iZ10 MX, using Attenuated Total Reflection (ATR) diamond corrector and a DTG detector in a reflectance mode from 4000 to $675 \mathrm{~cm}^{-1}$ with a resolution of $4 \mathrm{~cm}^{-1}$. All Fourier transform infrared spectroscopy FTIR analysis were carried out in combination with ATR, providing excellent quality data and the best possible reproducibility. This is a sampling method that enables direct examination of samples without further preparation of liquids, gases or solids.

The morphological characterization of feedstock powder and HA coatings was performed by Scanning Electron Microscopy SEM (ProX Phenom) equipped with Energy Dispersive Spectroscopy (EDS) for microanalysis. The phase identification of the powder and coating were analyzed by a X'Pert PRO MPD diffractometer (PANalytical). A Rietveld analysis, using the FullProf software [27], was carried out to refine the lattice parameters, determine the crystallite size and to find the percentage of the crystalline and amorphous phase [28]. The Thomson-Cox-Hastings pseudo-Voigt profile function was used for the refinement and the instrumental resolution was also introduced. In order to achieve a good correlation between the calculated and the experimental diffractograms, the minimum value of the usual fit indicators of the FullProf software were monitored (i.e. the refinement should give a reduced chisquared nearly equal to 1). The increase of peak half width respect the instrumental contribution is assumed to mainly come from the grain size and strain effects; the different proper parameters were fitted throughout the refinement. At each step, iteration cycles were conducted until convergence was reached. In order to evaluate the amorphous phase content, HA coating was detached from 
the substrate and crushed and mixed with a known weight of crystalline phase pattern, in our case alumina. It is possible to calculate directly the weight fractions of the crystalline phases $\mathrm{W}_{\mathrm{J}}$ and the weight fraction $\mathrm{W}_{\mathrm{AM}}$ of the amorphous phases just knowing the fraction in weight $\mathrm{W}_{\mathrm{P}}$ of the pattern (experimental weighted alumina fraction) and the weight fractions of the phases, $W_{J}^{O}$, quantified from the Rietveld refinement (including that of the pattern $W_{P}^{O}$ ), with the following equations:

$$
\text { (Eq.2) } W_{J}=\frac{W_{J}^{0}-W_{P}}{W_{P}^{0}(1-W p)} ; \quad \text { (Eq. 3) } W_{A M}=\frac{W_{P}^{0}-W_{P}}{W_{P}^{0}(1-W p)} \quad[28]
$$

The Cold Gas Spray equipment used is a CGS KINETICS® 4000 (Cold Gas Technology, Ampfing, Germany) with a maximum operating pressure of $40 \mathrm{bar}$, temperature of $800^{\circ} \mathrm{C}$ and operated with nitrogen as the propellant gas.

For the evaluation of single particle deposition, the so-called "wipe test" was performed, which consisted in particle deposition onto a mirror-like polished Ti6A14V alloy substrate at high gun traverse speed.

The HA coated sample from previous studies [29] was used for the study of particle-particle interaction. In order to examine those features, a thin lamella from HA particle, single splat and coating were obtained by Focused Ion Beam (FIB) lift-out technique and compared to the initial feedstock structure. A FEI Strata Dual Beam 235 system was used. Finally, transmission electron microscopy examinations were carried out using a JEM 2100 microscope, operated at $200 \mathrm{kV}$ (with current density of $80-250 \mathrm{pA} / \mathrm{cm}^{2}$ ). Much care was taken when irradiating the samples since some damage could be noticed through the observation; however, the use of a spread beam to acquire HRTEM images produces a decrease of the electron dose on the sample, which gave us the possibility to obtain such information without being significantly degraded.

In order to evaluate the adhesion, a Revetest (CSM Instrument) scratch equipment with a Rockwell C diamond indenter with a cone angle $120^{\circ}$ and tip radius $200 \mu \mathrm{m}$ was used. The scratch speed was from 0.4 to $600 \mathrm{~mm} / \mathrm{min}$ until a maximum load of $200 \mathrm{~N}$.

\section{Results and discussion}

\subsection{Characterization of feedstock powder}

Figure 1a displays the spherical morphology of HA particles with a particle size distribution of $-63+15 \mu \mathrm{m}$ and a mean diameter of $32.9 \mu \mathrm{m}$. The HA powder with a density of $0.55 \mathrm{~g} / \mathrm{cm}^{3}$ appears to be composed of very fine agglomerates (Fig.1b). TEM micrographs actually reveal a structure consisting of a needle-like morphology (Fig. 2a) whose electron diffraction exhibits a ring pattern denoting its nanocrystalline nature. At higher magnification, nanoparticle superposition becomes apparent, leading to the observation of Moiré fringes (Fig. 2b). It is, however, quite obvious the analogy with other works reporting these morphologies as a result of the reaction between calcium hydroxide and ortho-phosphoric acid: $5 \mathrm{Ca}(\mathrm{OH})_{2}+3 \mathrm{H}_{3} \mathrm{PO}_{4} \rightarrow \mathrm{Ca}_{5}\left(\mathrm{PO}_{4}\right)_{3}(\mathrm{OH})+9 \mathrm{H}_{2} \mathrm{O}[30]$. Upon heating the as supplied powder at temperatures above $800^{\circ} \mathrm{C}$, the structure completely changed from needle like to spheroidat, as shown in figure $2 \mathrm{c}[\mathrm{l}$.

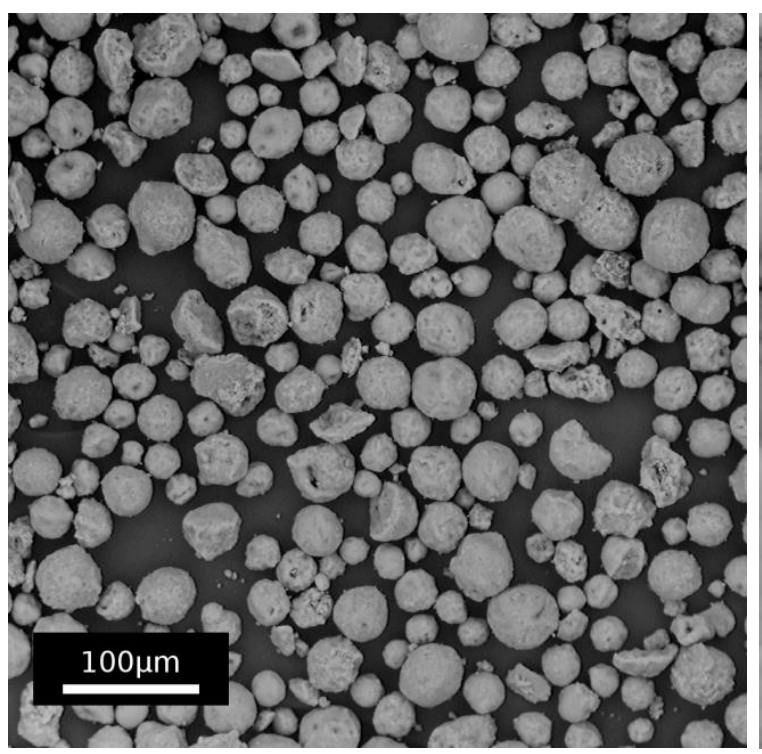

(a)

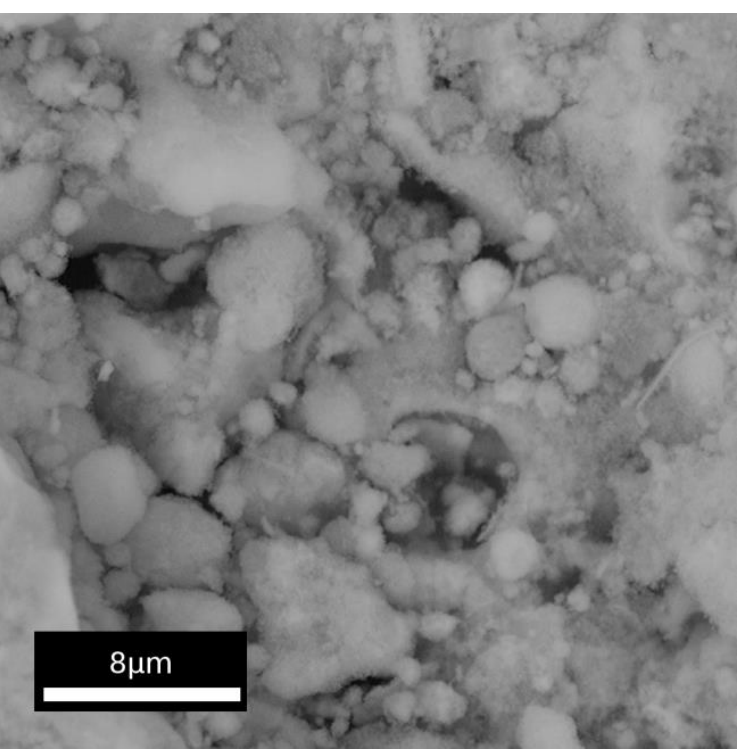

(b)

Figure 1: HA powder morphology at different magnifications 


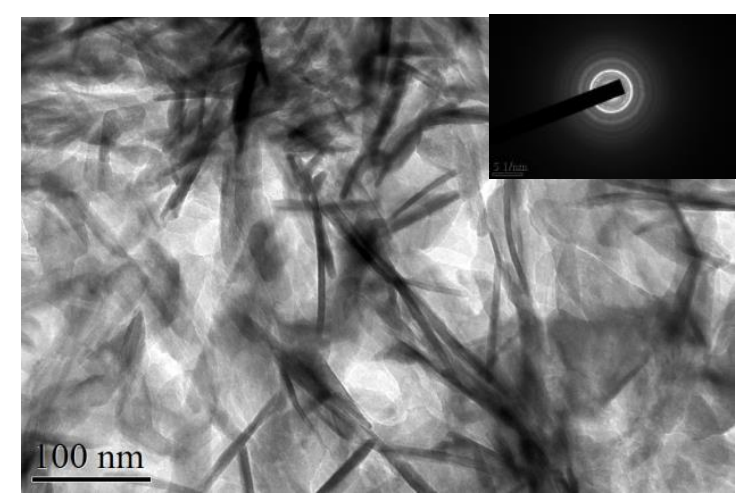

(a)

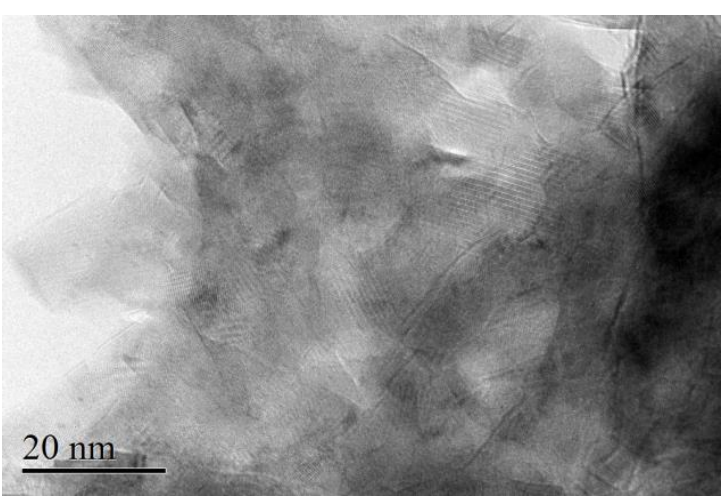

(b)

Figure 2: (a-b) TEM micrographs and SAED pattern of an agglomerated HA particle e) TEM micrographs of HA particle upon heating above $800^{\circ} \mathrm{C}$

Figure 3a shows the X-Ray Diffraction (XRD) pattern of the powder with broad peaks more likely as a consequence of the very small crystallite size. The identification revealed the presence of the 9-432 JCPDS HA syn. pattern corresponding to a hexagonal P63m/lattice, as well as the 9-080 JCPDS pattern, which corresponds to the monetite phase, a calcium hydroxide phosphate with triclinic lattice.

By using the FullProf software, the XRD pattern was refined (Fig. 3b) and the content of HA phase was found to be $88.65 \pm 0.28 \%$, the monetite phase $3.78 \pm 0.14 \%$ and the amorphous phase $7.56 \pm 0.15 \%$ [28]. The refined lattice dimensions were found to be the following: (i) $\mathrm{HA} \mathrm{a}=\mathrm{b}=9,429 \pm 0.13410^{-3} \mathrm{~A}, \mathrm{c}=6,892 \pm 0.09610^{-3} \mathrm{~A}$ and, (ii) monetite $\mathrm{a}=6,905 \pm 0.65610^{-3} \mathrm{~A}, \mathrm{~b}=6.642 \pm 0.55110^{-3}$ $\mathrm{A}, \mathrm{c}=7.001 \pm 1.19310^{-3} \mathrm{~A}, \alpha=96.423 \pm 0.014^{\circ}, \beta=103.873 \pm 0.015^{\circ}, \gamma=88.514 \pm 0.011^{\circ}$. The minimum value of the usual fit indicator Chi2 that was monitored by the FullProf software along the fitting was 5.45. A final crystallite value of $13.8 \mathrm{~nm}$ was found for the hydroxyapatite phase. According to [14], this grain size should be suitable for biological properties because is less than 100nm An energy dispersive spectroscopy (EDS) analysis for the HA powder indicated a $\mathrm{Ca} / \mathrm{P}$ ratio of 1.76 . Considering that a stoichiometric $\mathrm{HA}$ has a $\mathrm{Ca} / \mathrm{P}$ ratio of 1.67 , this indicates that they could directly bond to bone in contrast to calcium phosphates that have lower ratio of $\mathrm{Ca} / \mathrm{P}$ than 1.4 [31].

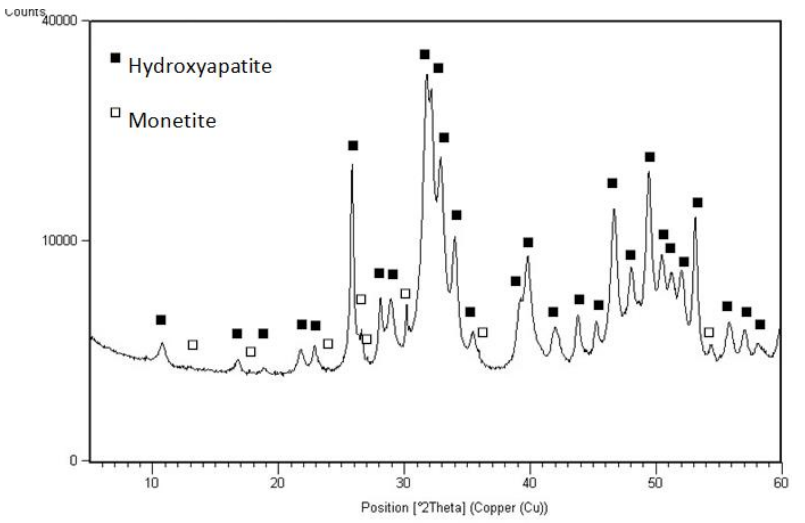

(a)

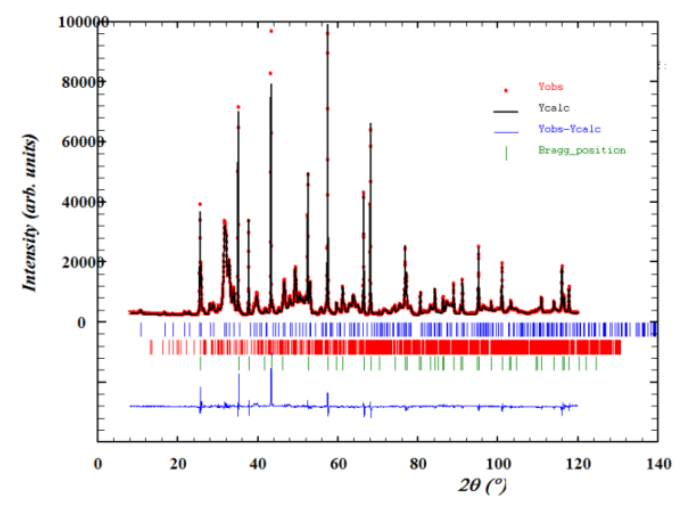

(b)

Figure 3: (a)XRD and (b) Rietveld analysis of the HA powder

FTIR spectrum of HA powder contains characteristic phosphate, carbonate and hydroxyl bands (Fig. 4) as presented in table 1. Theoretically, there are four vibrational modes present for phosphate ions, $v_{1}, v_{2}, v_{3}$ and $v_{4}$. The phosphate $v_{1}$ band is present at 962 $\mathrm{cm}^{-1}$ corresponding to non-degenerate symmetric P-O stretching, whereas the $\mathrm{v}_{3}$ region between $1190-976 \mathrm{~cm}^{-1}$ corresponds to antisymmetric P-O stretching and the 04 bands at 560,600 and $629 \mathrm{~cm}^{-1}$ corresponding to triply degenerated O-P-O bending. $v_{2}$ is not found in FTIR spectrum because of its wave number $\left(\mathrm{cm}^{-1}\right)$ is below the minimum of data spectrum [32]. Theoretically, carbonate ions have four vibrational modes, in which three of them can be observed in the infrared spectrum and two in Raman spectrum. Carbonate bands $v_{3}$ and $v_{2}$ are located in the region of $1650-1300 \mathrm{~cm}^{-1}$ and at $875 \mathrm{~cm}^{-1}$ respectively. Despite not distinguished by 
$\mathrm{XRD}$, the presence of carbonate ions may come from a reaction between carbon dioxide in air and the high $\mathrm{pH}$ precursor solution in powder production [33]. Finally, in comparison with other HA phases such as $\beta$-TCP, the OH- group two peaks are observed at $3569 \mathrm{~cm}^{-1}$ and a weaker one at $635 \mathrm{~cm}^{-1}$, which correspond respectively to the stretching and libration mode of hydroxyl vibrations typical of HA [34]. Figure 5 shows the TG curve for hydroxyapatite powder. The curve decreases progressively from 200 to $1300^{\circ} \mathrm{C}$. No significant peaks were observed, except for a weight loss of $\sim 4.5 \%$, which is assumed to be the result of gradual dehydroxylation of $\mathrm{HA}$ powder. This can be explained by the following reaction: $\left(\right.$ eq.4) $\mathrm{Ca}_{10}\left(\mathrm{PO}_{4}\right)_{6}\left(\mathrm{OH}_{2} \rightarrow\right.$ $\mathrm{Ca}_{10}\left(\mathrm{PO}_{4}\right)_{6}(\mathrm{OH})_{2-2 x} \mathrm{O}_{x} \square_{x}+x \mathrm{H}_{2} \mathrm{O}[35]$.

\begin{tabular}{clll}
\hline & HA POWDER & HA COATING \\
\hline \multicolumn{2}{l}{ Hydroxyl stretch $\mathbf{U}_{\mathbf{5}}$} & 3569 & 3570 \\
\hline \multicolumn{2}{c}{ Carbonate $\mathbf{U}_{\mathbf{3}}$} & 635 & 635 \\
$-\quad(\mathbf{m})$ & $1650-1300$ & $1650-1300$ \\
$-\quad(\mathbf{m})$ & 1641 & 1643 \\
$-\quad(\mathbf{m})$ & 1448 & 1446 \\
$-\quad(\mathbf{m})$ & 1417 & 1417 \\
\hline Phosphate $\mathbf{U}_{\mathbf{3}}$ & - & - \\
$-\quad(\mathbf{v s})$ & $1190-976$ & $1190-976$ \\
$-\quad(\mathbf{v s})$ & 1088 & 1087 (debil) \\
\hline Phosphate $\mathbf{U}_{\mathbf{1}}(\mathbf{m})$ & 1023 & 1022 \\
\hline Carbonate $\mathbf{U}_{\mathbf{3}}(\mathbf{m s})$ & 962 & 962 \\
\hline Phosphate $\mathbf{U}_{\mathbf{4}}$ & 875 & 875 \\
$-\quad(\mathbf{m})$ & $660-520$ & $660-520$ \\
$-\quad(\mathbf{v s})$ & 629 & 622 \\
$-\quad(\mathbf{v s})$ & 600 & 599 \\
\hline
\end{tabular}

Table 1. Infrared band positions for hydroxyapatite powder and coating

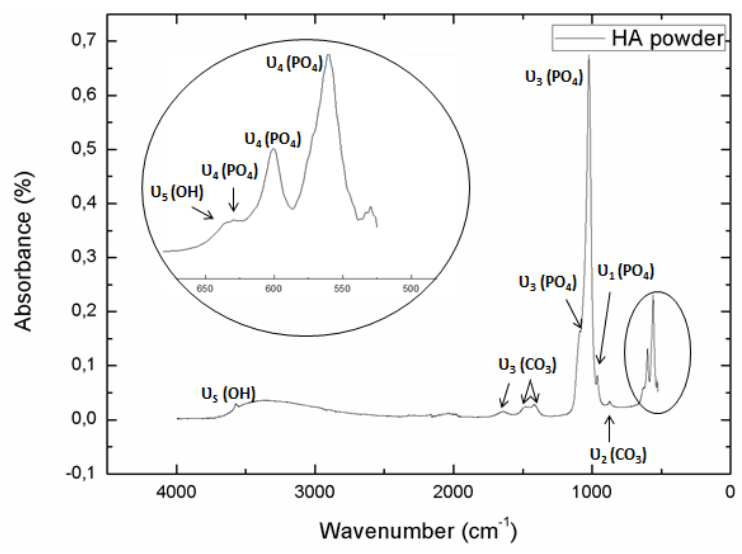

Figure 4: FTIR spectrum of the HA powder

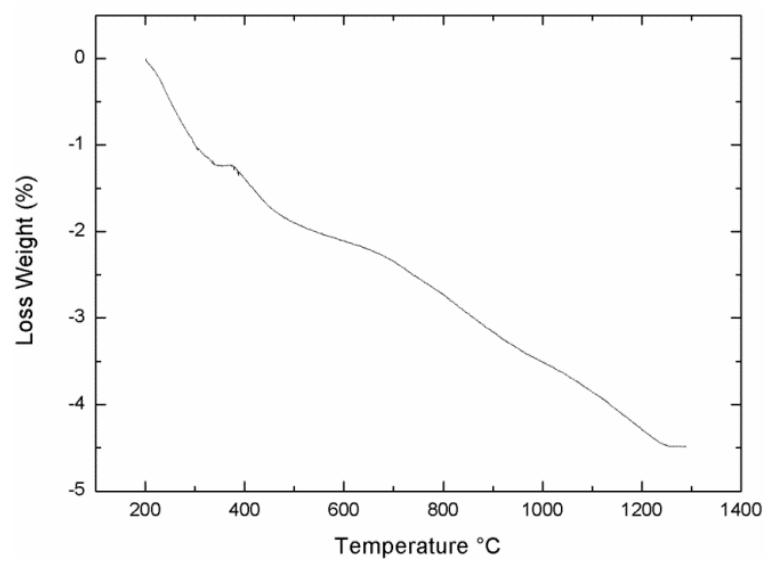

Figure 5: TG curve of HA powder 


\subsection{Characterization of coating build-up}

\subsubsection{Single particle study}

CS bonding mechanism in metals can be attributed to adiabatic shear instability which occurs at the particle/substrate or particle/deposited material interfaces at high impact particle velocities. However, the deposition of brittle or hard materials, such as ceramics, is still under research. Figure 6 a shows a general view of the wipe test on the Ti6Al4V substrate and figure $6 \mathrm{~b}$ is a magnification of a single deposited particle. A quite high particle deposition is observed and the absence of craters is an indication that upon the high shock pressure of the process and, given the hardness of the substrate and the agglomerated nature of the feedstock, the particles are more prone to spread over the surface rather that bouncing off leaving craters. This behavior is somehow different from what was observed within the previous study with the sintered feedstock powder where, when the particles did not properly bond, they left ring-shape morphologies with the central part of the splat bounced off. That performance was well in agreement to the stress distribution simulations usually carried out in CS which indicate that upon impact, tensile stresses may be developed at the center bottom of the splats resulting in detachment [36]. Similar ceramic particle behavior was found in the AD method. The $\mathrm{AD}$ method is based on shock-loading compaction due to the impact of ultrafine ceramic particles onto a surface. First, particles are mixed with a gas to generate an aerosol. During the impact onto the substrate, part of the particles kinetic energy is converted into thermal energy causing increase in temperature at the point-of-impact and promoting bonding between the substrate and the particles and also between multiple particles. The result is a process that yields an acceptable consolidation at room temperature without the need for a thermal treatment. This process is called room temperature impact consolidation (RTIC) [7].

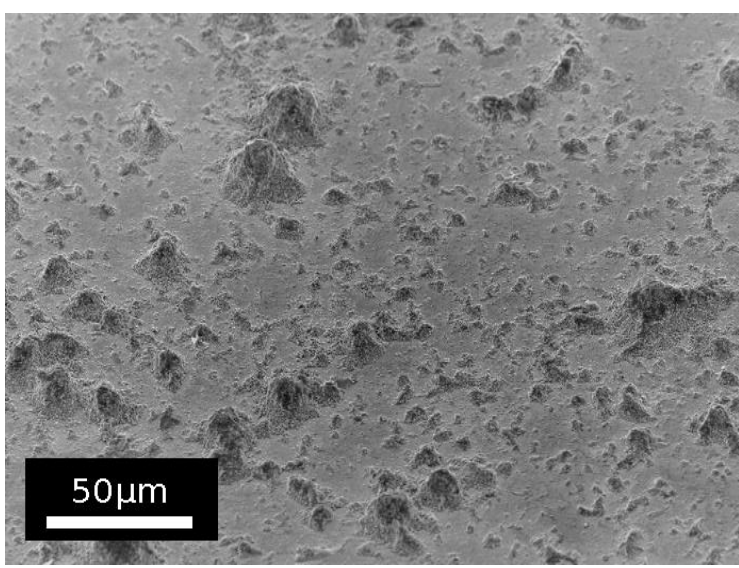

(a)

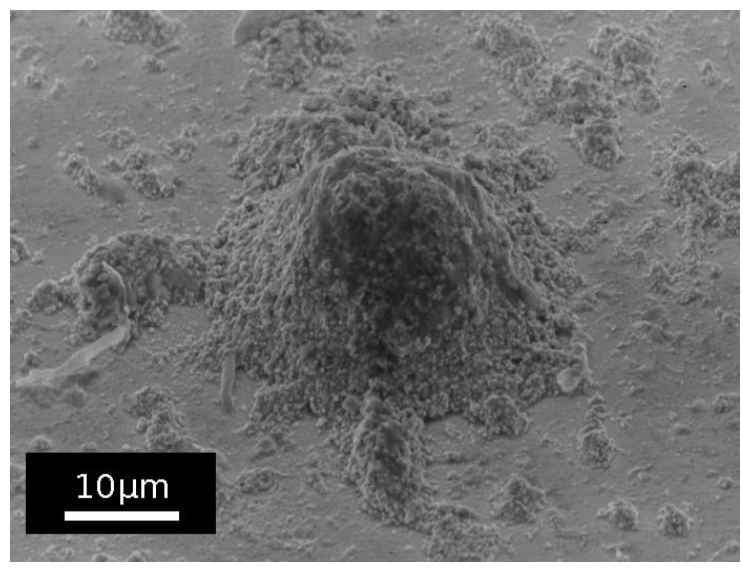

(b)

Figure 6: Wipe test of HA on the Ti6Al4V substrate at different magnifications

The morphology of CS HA bonded particles, either coming from a sintered feedstock or an agglomerate seem to be quite similar (Fig. 6) but further insight into the microstructure reveals the differences [24]. The nature of the powder exhibited in figure 2a and b made already foresee that its deposition would be quite different from that of sintered particles, i.e by pore collapsing and crushing. Therefore, the powder processing route is really important to be considered. A prepared FIB-splat lamella was prepared from HA splat (Fig. 7a). In general, at low magnification, a random orientation of the small crystallites was observed all over the splat (Fig. 7b). At certain zones, more in the upper side of the prepared FIB-splat lamella, the needle-like morphology can still be observed (Fig. 7c); some clearer areas are most likely artifacts related to the TEM specimen observation [37]. In other more inner regions (Fig. 7d), however, Moiré fringes are also observed but without observing such needle-like structure; rather, crystallite overlapping appears to be more significant. Figure 7e shows the region near the interface with the substrate, where such overlapping is visible. It

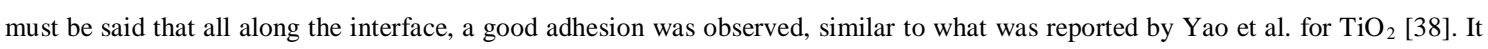
seems that the impact has produced compaction of nanocrystalline grains within the particle, preserving the nanoscale nature. This is slightly different from the room-temperature impact consolidation (RTIC) mechanism reported for AD [7] because it would first require fracturing of submicrometer particles. 


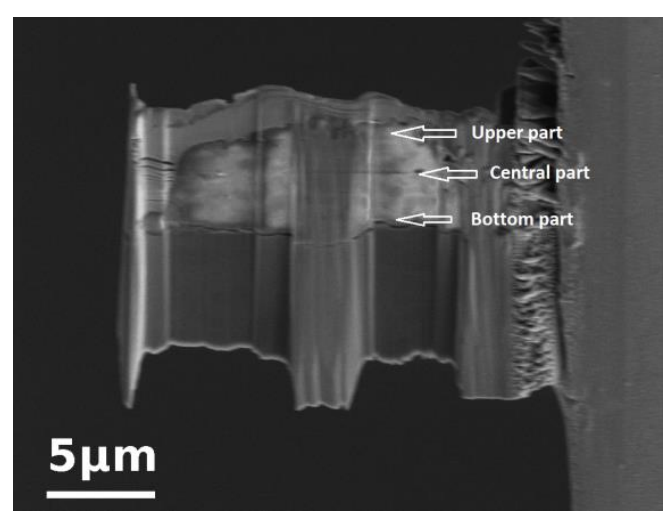

(a)

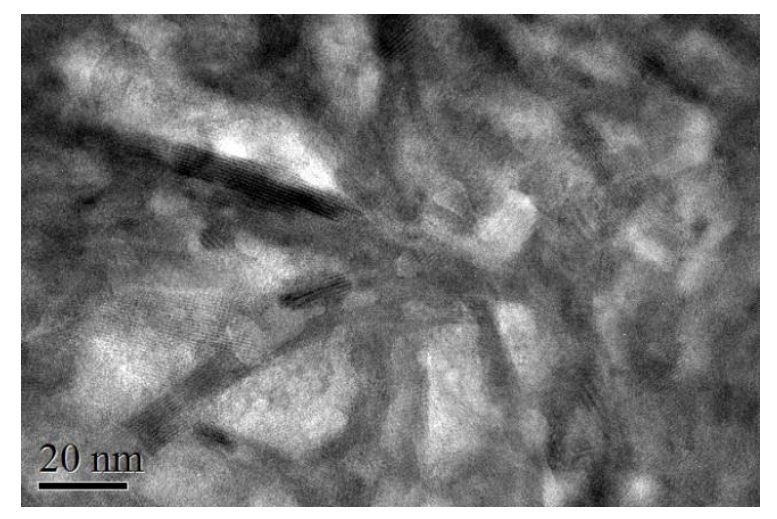

(c)

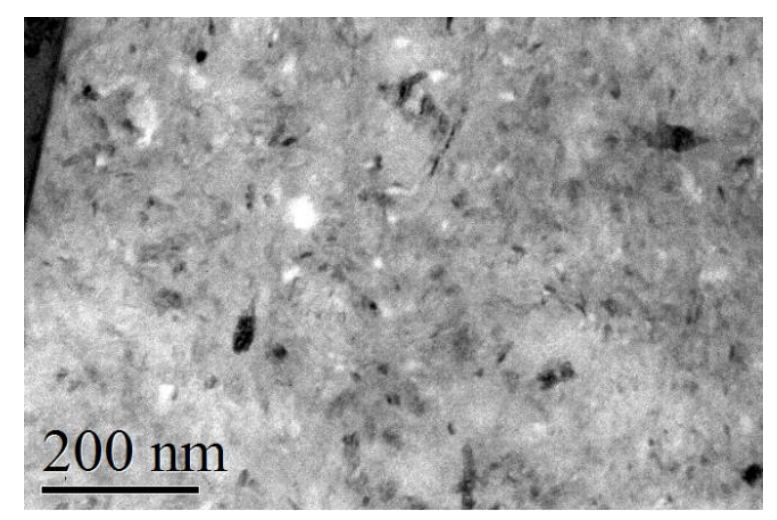

(b)

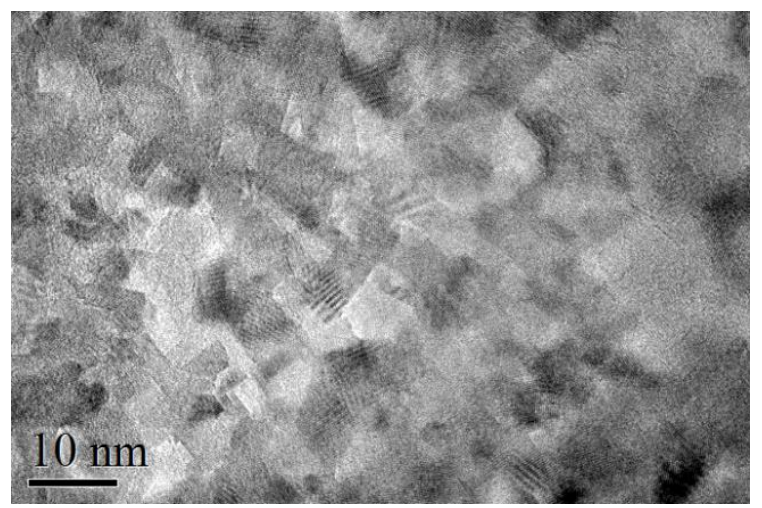

(d)

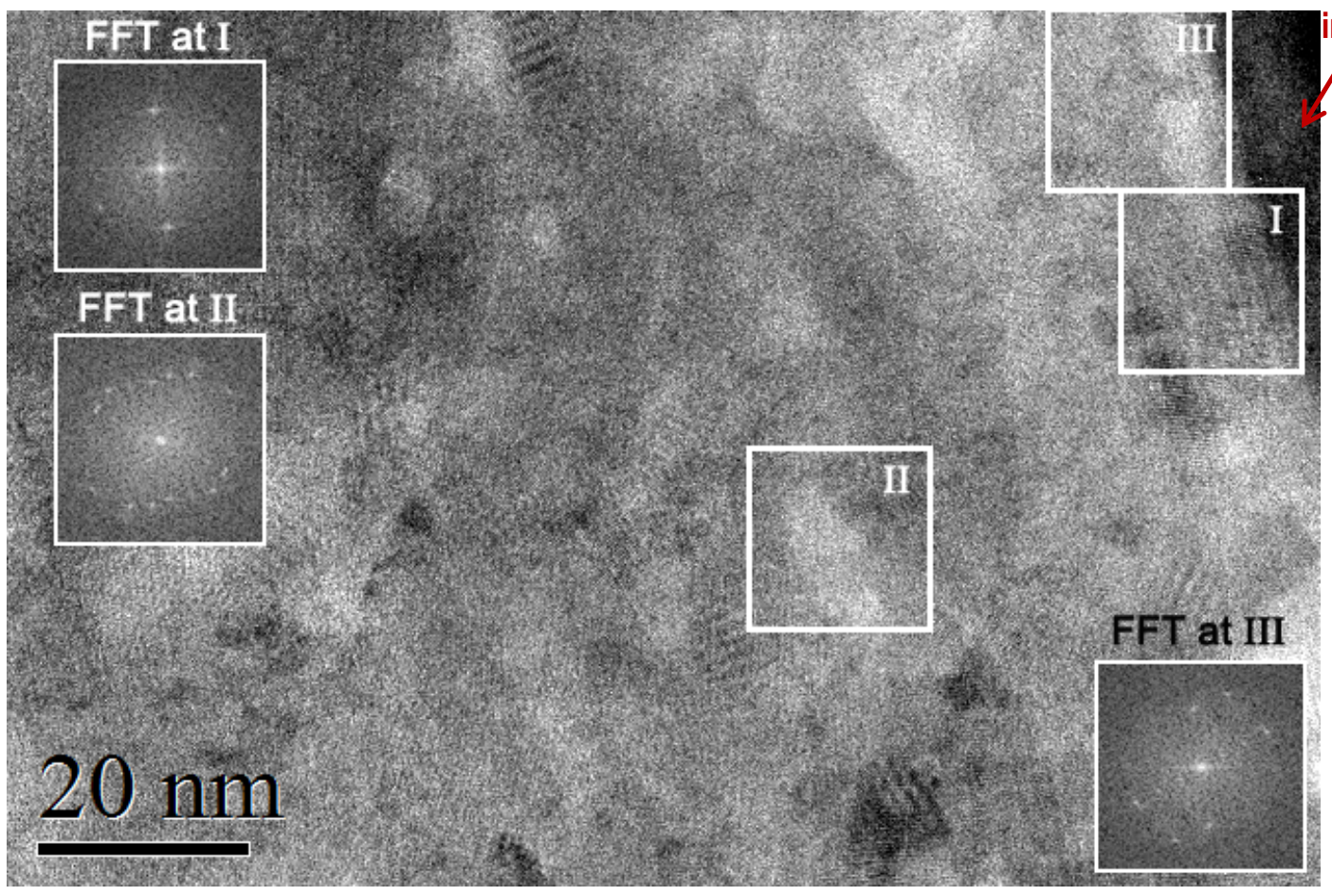

(e)

Figure 7: (a) FIB preparation of HA splat on Ti6Al4V alloy. (b) General TEM micrograph representative of the whole splat, (c) upper, (d)central and (e) bottom part of the HA splat onto Ti6Al4V 


\subsubsection{Coating deposition}

Thick HA coatings were achieved by CS (Fig. 8a). The top surface consists of a powdering texture, consistent with the observed agglomerated nature of the feedstock (Fig. 8b).

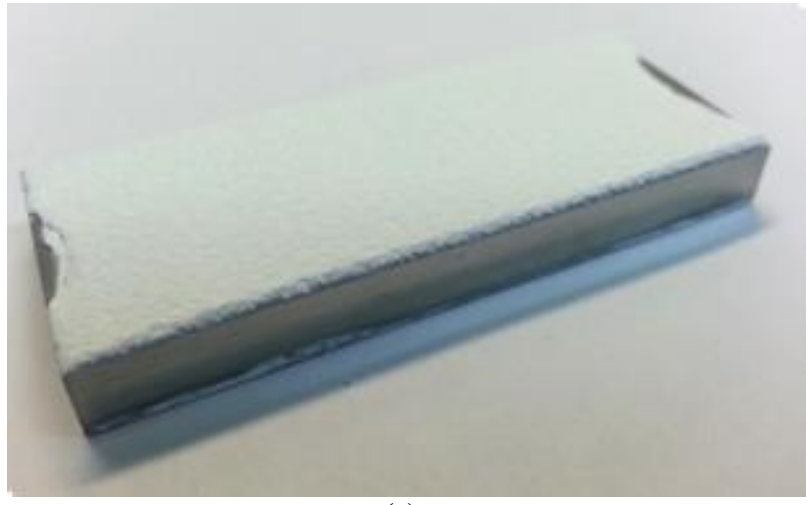

(a)

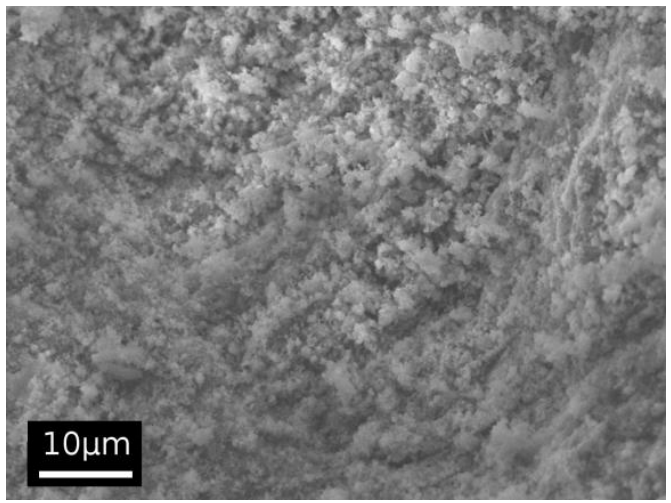

(b)

Figure 8: (a) Macrograph of HA coatings and (b) top surface SEM micrograph

Figure 9a shows the XRD pattern of the HA coating deposited by CS. The same phases were identified; the monetite phase has been found to be present already in the feedstock, so it is not produced as result of the thermal history of the powder in the gas stream, whose temperature is much lower than the typical temperatures of conventional thermal spray processes that produce powder decomposition. Both XRD patterns maintain similar peak broadness. By using the FullProf software, the Chi2 value obtained at the final fitting was 8.71. The XRD pattern was refined (Fig. 9b) and the content of the hydroxyapatite was found to be $86.58 \pm 0.47 \%$, the monetite phase $2.07 \pm 0.16 \%$ and the amorphous phase $11.34 \pm 0.20 \%$. It did not result then in any microstructural and compositional change. Also, a final value of $11 \mathrm{~nm}$ in crystallite size was found for the hydroxyapatite phase. No significant changes were thus perceived in comparison with feedstock powder; the HA powder preserved the nanoscale nature structure after CS deposition. Figure 10 shows the FTIR spectrum of the HA coating that contains the same characteristic phosphate, carbonate and hydroxyl bands as the FTIR spectrum of the HA powder (Fig.4), previously discussed. The unique difference between both spectrums is the intensity of the peaks, which are less intense in the HA coating because of the surface roughness. Actually, the main sampling problem in FTIR characterization of biomaterials is that nearly all solid materials are too opaque in their normal forms for direct transmission analysis in the mid-infrared region. This problem can be solved by reducing the optical density of samples to a suitable level by employing various sampling techniques but, since these procedures can alter the nature of the sample and are time consuming. For that, ATR was employed; however, it is limited in some applications due to stringent surface requirements. This confirms from the compositional point of view, that the feedstock composition is preserved after spraying.

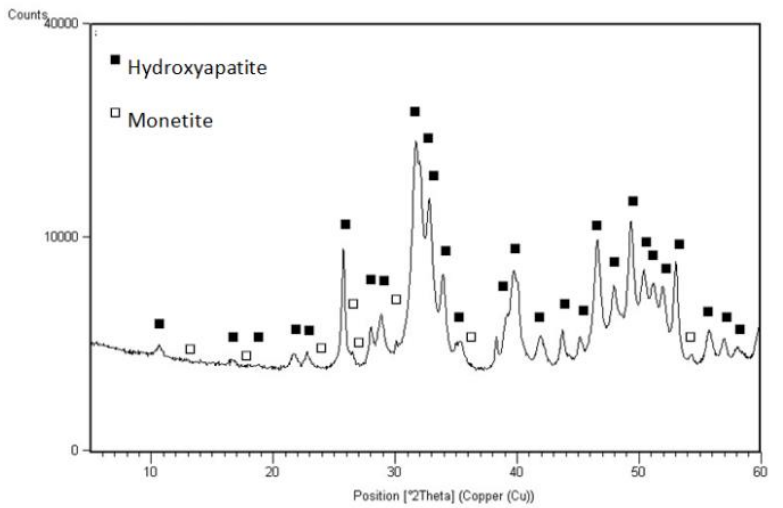

(a)

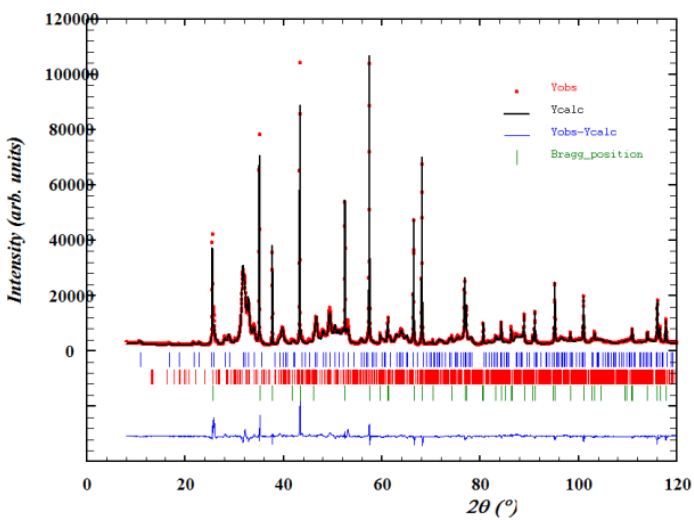

(b)

Figure 9: (a) X-ray diffraction and (b) Rietveld analysis of the HA coating 


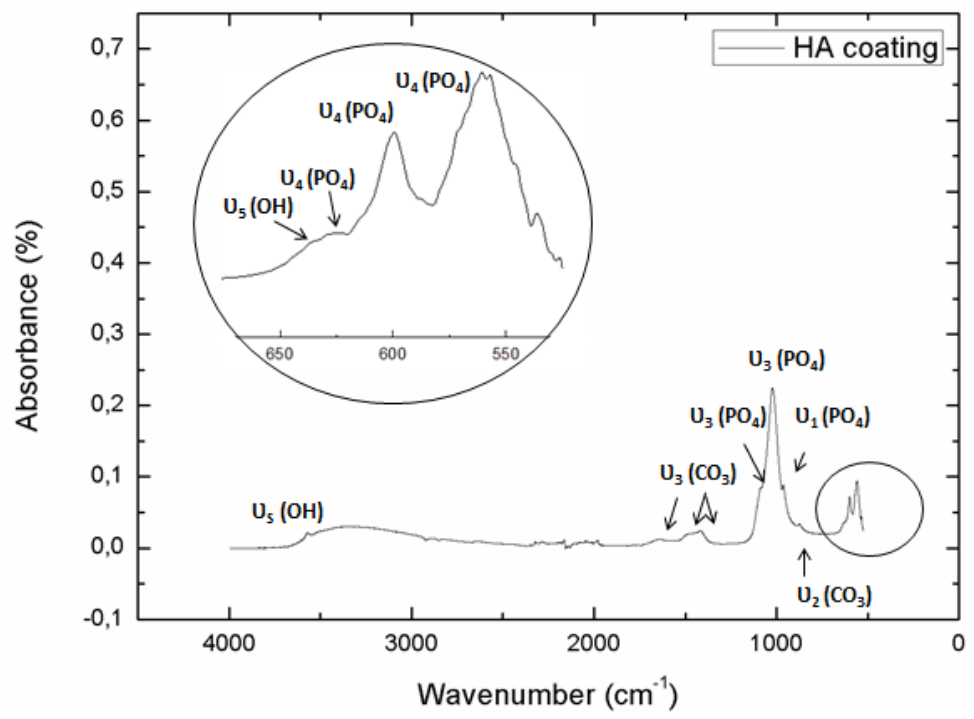

Figure 10: FTIR spectrum of the HA coating

The compacity of the coating and the interaction with the substrate were analyzed also by TEM. Several micrographs of different zones are shown in figures 11 and 12 showing the upper and bottom part of the section respectively. Moire patterns were observed as in the splat but the upper side (Fig. 11 and 12) exhibiting an effective consolidation. This must be due to the tamping effect produced by continuous impact of incoming particles onto the already adhered ones. Particle-particle boundaries are difficult to be recognized in figure 12. This might be explained by the shock compaction of nano-sized particles [39]. Mamalis et al. [40] related this shock compaction to the fracture of particles, filling the interstices, cleaning the surfaces and heating of the particle surfaces which lead to either partial surface melting and welding or solid-state diffusion bonding.

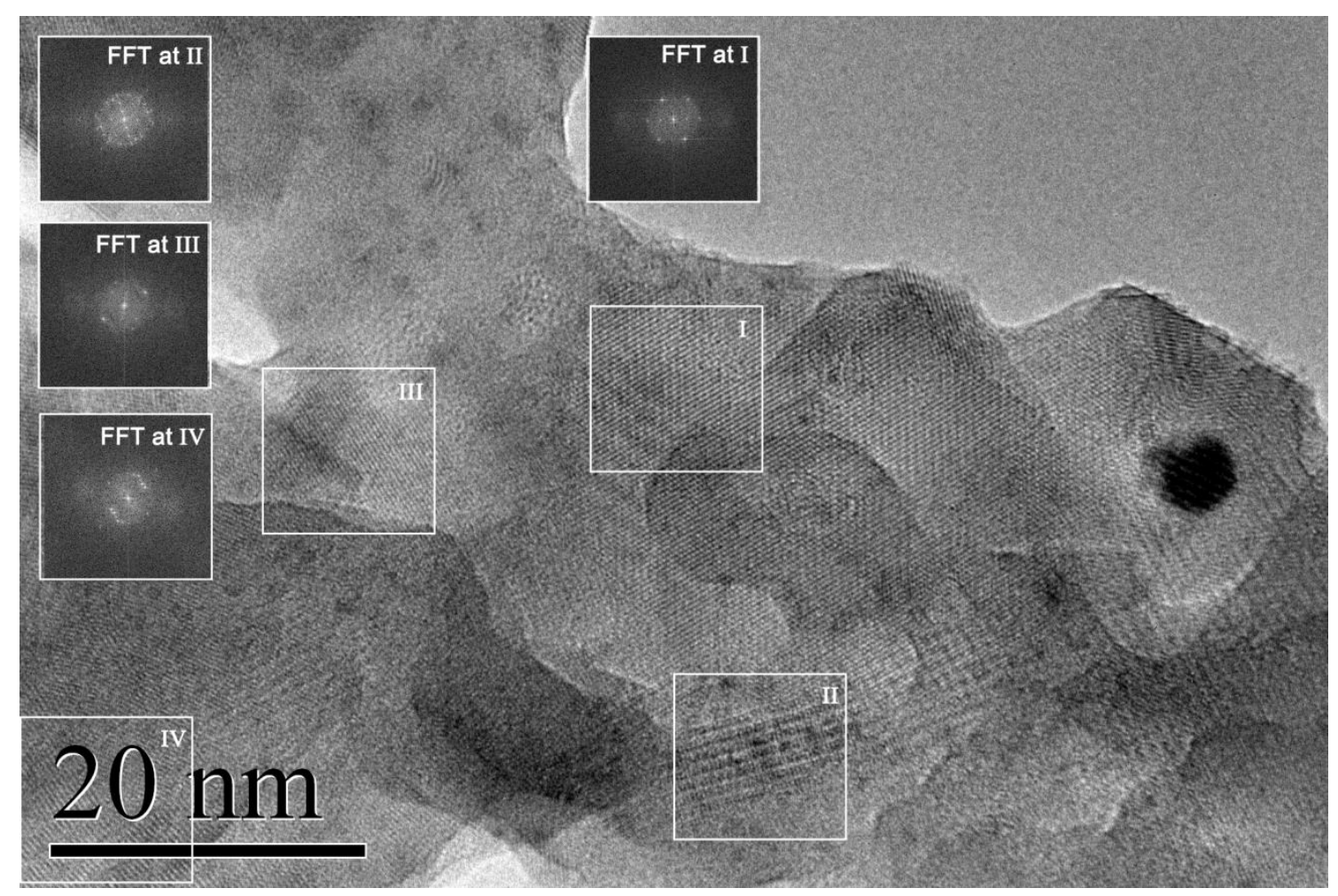

Figure 11: TEM micrograph of the upper part of HA coating 


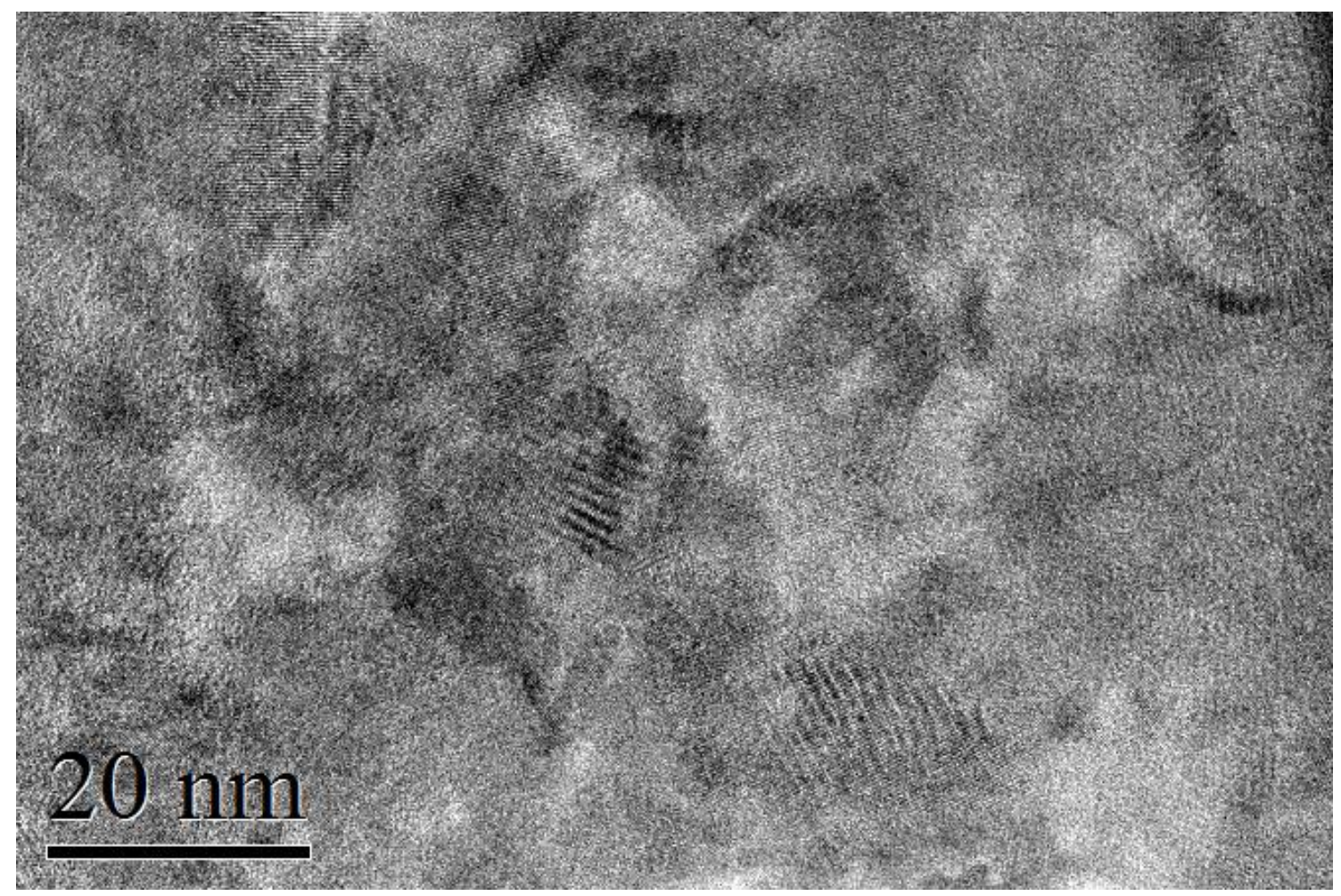

Figure 12: TEM micrograph of the bottom part of HA coating

This thermal effect is well included in the energy balance upon particle impact. The bonding mechanisms of metal particles within a coating deposited by CS are known to be predominantly by plastic deformation at high strain rates. The heat generated upon the impact may promote dynamic recrystallization or melting in shear bands, which are occurring at the interfacial regions, i.e. particlesubstrate or particle-particle interfaces. Since it has been proved that not enough heat is produced to be able to melt the impinging particle [41], the only heat considered for energetic considerations is that of adiabatic heating, dissipated locally at the interface via plastic deformation. A proper energy balance may be then the following: (Eq. 5) $\mathrm{E}_{\text {kinetic }}=\mathrm{E}_{\text {plastic }}+\mathrm{E}_{\text {thermal, }}$ where Dewar et al [42], were able to calculate the particle-substrate interface temperature assuming that none of the kinetic energy that is converted to heat is lost to the environment, to the rest of the bulk splat, or to the substrate. Obviously, this is an approximation since all the physical and thermal properties of the splat are assumed to be constant.

For the impact of a ceramic particle at low-temperature deposition systems, fragmentation phenomenon has also to be included through a failure model. The Johnson-Holmquist model contains a strength model and a failure model that was used by Chun et al. [39] to simulate the impact of an alumina particle by NPDS; this model uses the normalized stress and pressure values from the strength and pressure components of the Hugoniot elastic limit $\left(\sigma_{\mathrm{HEL}}, \mathrm{P}_{\mathrm{HEL}}\right)$. In this case, the kinetic energy is transformed into thermal and fragmentation energies: (Eq. 6) $E_{\text {kinetic }}=E_{\text {fracture }}+E_{\text {thermal }}={ }_{2}^{1} P\left(V_{00}-V_{0}\right)$, where $V_{00}$ and $V_{0}$ are the specific volumes of the porous and solid material respectively. As already commented previously, the fracturing depends on the shock intensity and therefore to the impact conditions and, on the powder initial density.

If we consider a sintered particle, it is obvious that $\mathrm{E}_{\text {fracture }}$ can be significant and the gaps of the initial pores can be more or less effectively filled depending on the impact conditions; this can also result in the presence of plastic deformation mechanism. According to the simulations of Akedo et al. [8], the maximum rising impact pressure was almost the same as the experimental fracture toughness of the starting particle and enough to destroy the particle.

In the present case, however, the feedstock is not sintered and, therefore, $E_{\text {fracture }}$ is assumed to be low and most of the kinetic energy is transformed into thermal energy. The particle density is $3,001 \mathrm{~g} / \mathrm{cm}^{3}$ for the sintered particles in [24] and, as said before, 0,55 $\mathrm{g} / \mathrm{cm}^{3}$ for the agglomerated particles of the present work; therefore, for the same particle size, the lower mass of the agglomerated particles leads to lower kinetic energy. Then, the temperature rise is obviously not high enough to produce sintering since the

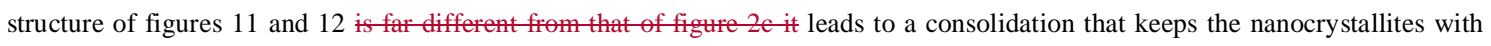
good cohesion. 
A first approach to calculate the mechanical properties was performed by the scratch test. A thick HA coating with approximately $350 \mu \mathrm{m}$ showed a critical load of $53 \pm 10 \mathrm{~N}$, while a thin carbonated biomimetic nanocrystalline appatite coating by CS with a thickness of about $60 \mu \mathrm{m}$ showed a value of $7 \pm 2 \mathrm{~N}$ [43]. On the other hand, HA coatings with a $150 \mu \mathrm{m}$ thickness were obtained by PS onto titanium, indicating a critical load of $12.3 \mathrm{~N}$, and $10.5 \mathrm{~N}$ onto aluminum [44]. HA coatings also were obtained by microplasma spraying [45], and it was observed that for a HA coating, with a thickness of $232 \pm 8.25 \mu \mathrm{m}, 91.6 \%$ of crystallinity and a $19.17 \pm 1.98 \%$ of porosity, the critical normal load that caused localized delamination through microcracking was $\sim 400 \mathrm{mN}$.

\section{Conclusions}

Cold Spray has been shown to be a suitable technique to deposit nanocrystalline hydroxiapatite particles. TEM micrographs actually reveal a structure consisting of a needle-like morphology. It seems that the impact has produced compaction of nanocrystalline grains within the particle. Moiré patterns were observed as in the splat but the upper side shows partial contacts between crystallites while the bottom side exhibits much more effective consolidation. This must be due to the tamping effect produced by continuous impact of incoming particles onto the already adhered ones. Powder and coating characterization confirm that there is no amorphization of HA and the microstructure is preserved. Moreover, no size changes were detected in nano-sized grains by TEM.

\section{Acknowledgements}

This work was supported by the Generalitat de Catalunya for the project [2014 SGR 1558]; the University of Barcelona for the award of APIF scholarship that has allowed the development of this project.

\section{REFERENCES}

[1] B. Chambers, S.F. St. Clair, M.I. Froimson, Hydroxyapatite-Coated Tapered Cementless Femoral Components in Total Hip Arthroplasty, J. Arthroplasty. 22 (2007) 71-74.

[2]Y.-L. Chen, T. Lin, A. Liu, M.-M. Shi, B. Hu, Z. Shi, et al., Does hydroxyapatite coating have no advantage over porous coating in primary total hip arthroplasty? A meta-analysis, J. Orthop. Surg. Res. 10 (2015) 1-14.

[3] Y.C. Tsui, C. Doyle, T.W. Clyne, Plasma sprayed hydroxyapatite coatings on titanium substrates Part 1: Mechanical properties and residual stress levels, Biomater. 19 (1998) 2015-2029.

[4] A. Bernhardt, R. Dittrich, A. Lode, F. Despang, M. Gelinsky, Nanocrystalline spherical hydroxyapatite granules for bone repair: in vitro evaluation with osteoblast-like cells and osteoclasts, J. Mater. Sci.: Mater. Med. 24 (2013) 1755-1766.

[5] A.M. Vilardell, N. Cinca, A. Concustell, S. Dosta, I.G. Cano, J.M. Guilemany, Cold spray as an emerging technology for biocompatible and antibacterial coatings: state of art, J. Mater. Sci. 50 (2015) 4441-4462.

[6] J. Akedo, Aerosol Deposition Method for Fabrication of Nano Crystal Ceramic Layer, Mater. Sci. Forum. (2004) 43-48

[7] J. Akedo, Room Temperature Impact Consolidation (RTIC) of Fine Ceramic Powder by Aerosol Deposition Method and Applications to Microdevices, J.Therm. Spray Technol.. 17 (2008) 181-198. dei:10.1007/s11666-00891637.

[8] J. Akedo, Aerosol Deposition of Ceramic Thick Films at Room Temperature: Densification Mechanism of Ceramic Layers, J. Am. Ceram. Soc. 89 (2006) 1834-1839. doi:10.1111/j.1551 2916.2006.01030.x.

[9] M.-S. Kim, D.-M. Chun, J.-O. Choi, J.-C. Lee, K.-S. Kim, Y. Kim, et al., Room temperature deposition of TiO2 using nano particle deposition system (NPDS): Application to dye-sensitized solar cell (DSSC), Int. J. Precis. Eng. Manuf. 12 (2011) 749-752.

[10]D.-M. Chun, J.-O. Choi, C.S. Lee, S.-H. Ahn, Effect of stand-off distance for cold gas spraying of fine ceramic particles $(<5 \mu \mathrm{m})$ under low vacuum and room temperature using nano-particle deposition system (NPDS), Surf. Coat. Tech. 206 (2012) $2125-2132$. 
[11] B.-D. Hahn, D.-S. Park, J.-J. Choi, J. Ryu, W.-H. Yoon, K.-H. Kim, et al., Dense Nanostructured Hydroxyapatite Coating on Titanium by Aerosol Deposition, J. Am. Ceram. Soc. 92 (2009) 683-687.

[12] B.-D. Hahn, J.-M. Lee, D.-S. Park, J.-J. Choi, J. Ryu, W.-H. Yoon, et al., Mechanical and in vitro biological performances of hydroxyapatite-carbon nanotube composite coatings deposited on Ti by aerosol deposition, Acta Biomater. 5 (2009) 3205-3214.

[13] B.-D. Hahn, D.-S. Park, J.-J. Choi, J. Ryu, W.-H. Yoon, J.-H. Choi, et al., Aerosol deposition of hydroxyapatite-chitosan composite coatings on biodegradable magnesium alloy, Surf. Coat. Tech. 205 (2011) 3112-3118.

[14] T.J. Webster, C. Ergun, R.H. Doremus, R.W. Siegel, R. Bizios, Enhanced functions of osteoblasts on nanophase ceramics, Biomater. 21 (2000) 1803-1810.

[15] VK.Champagne. The cold spray materials deposition process: fundamentals and applications. Woodhead, Cambridge

[16] R. Ghelichi, M. Guagliano, Coating by the Cold Spray Process: a state o the art, Fratt Integr. Strutt. 8 (2009) 30-44.

[17] HR. Singh, TS. Sidhu, SBS. Kalsi, Cold spray technology: future of coating deposition processes. Fratt. Integr. Strutt. 22 (2012) 69-84.

[18] S. Dosta, M. Couto, J.M. Guilemany, Cold spray deposition of a WC-25Co cermet onto Al7075-T6 and carbon steel substrates, Acta Mater. 61 (2013) 643-652.

[19] A. Choudhuri, PS. Mohanty, J. Karthikeyan, Bio-ceramic composite coatings by cold spray technology. In: Proceedings of the International Thermal Spray Conference, (2009) 391-96

[20] X. Zhou (2012) Hydroxyapatite/titanium composite coating for biomedical applications. PhD thesis. University of Michigan

[21] J.H. Lee, H.L. Jang, K.M. Lee, H.-R. Baek, K. Jin, K.S. Hong, et al., In vitro and in vivo evaluation of the bioactivity of hydroxyapatite-coated polyetheretherketone biocomposites created by cold spray technology, Acta Biomater. 9 (2013) 6177-6187.

[22] A.W. Noorakma, H. Zuhailawati, V. Aishvarya, B.K. Dhindaw, Hydroxyapatite-Coated Magnesium-Based Biodegradable Alloy: Cold Spray Deposition and Simulated Body Fluid Studies, J. Mater. Eng. Perform. 22 (2013) 2997-3004.

[23]Y. Liu, J. Huang, H. Li, Nanostructural Characteristics of Vacuum Cold-Sprayed Hydroxyapatite/Graphene-Nanosheet Coatings for Biomedical Applications, J. Therm. Spray Technol. 23 (2014) 1149-1156.

[24] N. Cinca, A.M. Vilardell, S. Dosta, A. Concustell, I. Garcia Cano, J.M. Guilemany, et al., A New Alternative for Obtaining Nanocrystalline Bioactive Coatings: Study of Hydroxyapatite Deposition Mechanisms by Cold Gas Spraying, J. Am. Ceram. Soc. (2016) 1-9.

[25] L. Zhang, WT. Zhang, Numerical investigation on Particle Velocity in Cold Spraying of Hydroxyapatite Coating, Adv. Mater. Res. 18 (2011) 717-722.

[26] RP. Singh, B. Batra, Effect of Cold Spraying Parameters and their interaction an Hydroxyapatite Deposition, J. Appl. Fluid Mech. 6 (2013) 555-561.

[27] J. Rodriguez-Carvajal Introduction to the Program FULLPROF: Refinement of Crystal and Magnetic Structures from Powder and Single Crystal Data

[28] X.Alcobé. El método de rietveld en el caso de muestras multifásicas. Análisis cuantitativo. Apectos prácticos y ejemplos. XIII Escuela sobre el Metodo Rietvld, Universidad Jaume I Castellón (2013) 
[29] AM. Vilardell, N. Cinca, S. Dosta, IG. Cano, JM. Guilemany, Mulifuctional miro-nano structured hydroxyapatite Coatings on tianum Ti6Al4V for biomedical Applications by Cold Gas Spray, Núm. de solicitud: 809 País de prioridad: ESPAÑA Entidad Titular: UBAR - Universitat de Barcelona. Depósito Legal: 17/04/2015

[30] R. Kumar, K.H. Prakash, P. Cheang, K.A. Khor, Temperature Driven Morphological Changes of Chemically Precipitated Hydroxyapatite Nanoparticles, Langmuir. 20 (2004) 5196-5200.

[31] De Groot, K., Klein, C. P. A. T., Wolke, J. D., \& de Blieck-Hogervorst, J. M. A. (1990). Chemistry of calcium phosphate bioceramics. Handbook of bioactive ceramics, 2, 3-16.

[32] I. Rehman, W. Bonfield, Characterization of hydroxyapatite and carbonated apatite by photo acoustic FTIR spectroscopy, J. Mater. Sci. Mater. Med. 8 (1997) 1-4.

[33] K. Venkateswarlu, A. Chandra Bose, N. Rameshbabu, X-ray peak broadening studies of nanocrystalline hydroxyapatite by Williamson-Hall analysis, Physica B: Condensed Matter. 405 (2010) 4256-4261.

[34] L. Berzina-Cimdina, N. Borodajenko, Research of Calcium Phosphates Using Fourier Transform Infrared Spectroscopy, in: T. Theophile (Ed.), Infrared Spectroscopy - Materials Science, Engineering and Technology, InTech, 2012. http://www.intechopen.com/books/infrared-spectroscopy-materials-science-engineering-and-technology/research-of-calciumphosphates-using-fourier-transformation-infrared-spectroscopy (accessed November 14, 2016).

[35] B.C. Idrissi, K. Yamni, A. Yacoubi, A. Massit, A novel method to synthesize nanocrystalline hydroxyapatite: characterization with X-ray diffraction and infrared spectroscopy. IOSR J. Appl. Chem. 7 (2007) 107-112.

[36] K. Kim, M. Watanabe, S. Kuroda, Jetting-Out Phenomenon Associated with Bonding of Warm-Sprayed Titanium Particles onto Steel Substrate, J Therm. Spray Technol. 18 (2009) 490-499.

[37] J. Reyes-Gasga, R. Garcia-Garcia, E. Brès, Electron beam interaction, damage and reconstruction of hydroxyapatite, Physica B: Condens Matter. 404 (2009) 1867-1873.

[38] H.-L. Yao, G.-J. Yang, S.-Q. Fan, C.-X. Li, C.-J. Li, Ceramic Nano-particle/Substrate Interface Bonding Formation Derived from Dynamic Mechanical Force at Room Temperature: HRTEM Examination, J. Therm. Spray Technol. 24 (2015) 720-728.

[39] D.-M. Chun, S.-H. Ahn, Deposition mechanism of dry sprayed ceramic particles at room temperature using a nano-particle deposition system, Acta Mater. 59 (2011) 2693-2703.

[40] A. Mamalis, I.. Vottea, D.. Manolakos, On the modelling of the compaction mechanism of shock compacted powders, J. Mater. Process Tech. 108 (2001) 165-178.

[41]T. Schmidt, H. Assadi, F. Gärtner, H. Richter, T. Stoltenhoff, H. Kreye, et al., From Particle Acceleration to Impact and Bonding in Cold Spraying, J. Therm. Spray Technol. 18 (2009) 794-808.

[42] M.P. Dewar, A.G. McDonald, A.P. Gerlich, Interfacial heating during low-pressure cold-gas dynamic spraying of aluminum coatings, J. Mater. Sci. 47 (2011) 184-198.

[43] E. Kergourlay, D. Grossin, N. Cinca, First Cold Spraying of Carbonated Biomimetic Nanocrystalline Apatite on Ti6Al4V: Physical-Chemical, Microstructural, and Preliminary Mechanical Characterizations, Adv. Eng. Mater. 18 (2016) 496-500

[44] S. Kozerski, L. Pawlowski, R. Jaworski, F. Roudet, F. Petit, Two zones microstructure of suspension plasma sprayed hydroxyapatite coatings, Surf Coat Tech. 204 (2010) 1380-1387. 
[45] A. Dey, A.K. Mukhopadhyay, S. Gangadharan, M.K. Sinha, D. Basu, Characterization of Microplasma Sprayed Hydroxyapatite Coating, J. Therm. Spray Technol. 18 (2009) 578-592. 